\title{
Huperzine A inhibits immediate addictive behavior but not behavioral sensitization following repeated morphine administration in rats
}

\author{
JINLINGSUN, LIN TIAN, RUISI CUI and XINWANG LI \\ Beijing Key Laboratory of Learning and Cognition, \\ Department of Psychology, Capital Normal University, Beijing 100048, P.R. China
}

Received October 19, 2015; Accepted November 18, 2016

DOI: 10.3892/etm.2017.4097

\begin{abstract}
Acetylcholinesterase inhibitors are regarded as promising therapeutic agents to treat addiction. The current study aimed to examine the effects of huperzine A, a cholinesterase inhibitor, on behavioral sensitization induced by repeated morphine administration and relapse induced by contextual conditioning. The present study also assessed whether the state-dependency hypothesis may explain the results. Adult rats were divided into four groups $(n=8)$ and intraperitoneally injected with $0.2,0.3$ or $0.4 \mathrm{mg} / \mathrm{kg}$ huperzine A or saline ( $1 \mathrm{ml} / \mathrm{kg}$, control), for 5 days. The effect of repeated huperzine A administration alone on locomotor activity was assessed. For the experiments that analyzed the development of morphine-induced sensitization, 40 rats were divided into five groups $(n=8)$ : Saline+Saline, Saline+Morphine, 0.2, 0.3 and $0.4 \mathrm{mg} / \mathrm{kg}$ huperzine A+Morphine. Following a withdrawal period of 7 days, all animals were administered saline or morphine, as appropriate. To test the state-dependency hypothesis, the rats in the Saline+Morphine group were injected with saline and morphine, while the other three groups were administered different doses of huperzine A and morphine. To examine the effect of huperzine A on the expression of morphine-induced sensitization, the rats in huperzine A+Morphine groups were injected with appropriate concentrations of huperzine A, and morphine. The current results indicated that the administration of huperzine A alone did not affect locomotor activity, while higher doses of huperzine $\mathrm{A}$ inhibited the addictive behavior induced by morphine at the development phase. Additionally, huperzine A administration during the expression phase of morphine sensitization did not inhibit the relapse induced by administration of saline.
\end{abstract}

Correspondence to: Dr Xinwang Li, Beijing Key Laboratory of Learning and Cognition, Department of Psychology, Capital Normal University, 105 West 3rd Ring Road North, Beijing 100048, P.R. China

E-mail: lixw701@sina.cn

Key words: cholinesterase inhibitor, huperzine A, morphine, behavioral sensitization
Furthermore, $0.4 \mathrm{mg} / \mathrm{kg}$ huperzine A inhibited the expression of morphine-induced behavioral sensitization. Therefore, the results of the current study do not support the state-dependency hypothesis.

\section{Introduction}

Huperzine A is an acetylcholinesterase inhibitor isolated from the Chinese herb Huperzia serrata. It easily penetrates the blood-brain barrier (1) and possesses diverse pharmacological functions $(2,3)$. Huperzine A protects cortical neurons from $\beta$-amyloid-induced apoptosis in vitro (4), and regulates the expression of nerve growth factor and its receptors (5). Importantly, it selectively inhibits acetylcholinesterase (6). Compared with other acetylcholinesterase inhibitors, including physostigmine, donepezil and rivastigmine, huperzine $\mathrm{A}$ is more effective at increasing the level of cortical acetylcholine and has a longer lasting effect $(6,7)$. Currently, huperzine $\mathrm{A}$ is being investigated as a potential treatment for neurodegenerative diseases, such as Alzheimer's disease $(8,9)$. Additionally, acetylcholinesterase inhibitors have been recognized as promising therapeutic agents for drug addiction (10). Therefore, assessing the effects of huperzine A on drug addiction is important.

It has been suggested that behavioral sensitization is linked to drug craving and compulsive drug seeking (11). Behavioral sensitization refers to a phenomenon characterized by enhanced responsiveness following repeated, intermittent treatment with psychomotor stimulants $(12,13)$. Locomotor activity, as a measure of spontaneous behavior, has been primarily assessed in behavioral sensitization studies $(14,15)$. Additionally, behavioral sensitization has been established in rodents that have repeatedly been administered the same or incremental doses of a drug (16-19). It has been demonstrated that behavioral sensitization may also be applied in a model of testing addictive behavior associated with drug seeking and relapse $(12,20)$. Relapse is the resumption of drug seeking/drug consumption following a protracted period abstinence (14). In an animal model of relapse, when contextual conditioning is repeatedly paired with drug abuse, it has a distinct 'incentive salience', consequently leading to compulsive drug craving, seeking and relapse (21-23). Theories of contextual conditioning emphasize 
that a 'context' not only consists of fixed geometric features of the environment but also includes multi-modal sensory (visual, tactile and olfactory) cues and temporal or episodic context (24). A previous study has determined that the contextual conditioning may modulate behavioral effects of drug abuse, such as the sensitization to psychomotor stimulant effects of amphetamine (23).

Carlezon et al (25) and Wise et al (26) proposed the 'state-dependency' hypothesis based on studies of bromocriptine sensitization. This hypothesis suggests that sensitized behavior should only be evident under the same conditions in which the same type of drugs (an addictive drug and a non-addictive drug) and dosage were injected just as sensitized behavior was exhibited in the past. Therefore, sensitized response exhibited while under the influence of both drugs may only be recalled when a rat is in the same state. The rats did not exhibit sensitization when they were challenged with the addictive drug alone, which was due to the different states in which the sensitized behavior developed. Therefore, it has been suggested that state-dependency should be considered in studies that involve the inhibition of behavioral sensitization (27).

The purpose of the present study was to examine the effects of huperzine A on behavioral sensitization caused by morphine and relapse induced by contextual conditioning. It was also assessed whether the state-dependency hypothesis may explain the effects of huperzine A on morphine-induced sensitization.

\section{Materials and methods}

Animals. A total of 72 Male Wistar rats used in this study were 8 weeks old and weighted 220-250 g (Academy of Military Medical Sciences, Beijing, China). They were housed in groups of three per cage in a 12-h light-dark cycle (lights on at 7:00 a.m.) at $22 \pm 1^{\circ} \mathrm{C}$ and relative humidity of $50-60 \%$ with ad libitum access to food and water. Prior to the study experiments, animals were provided adaptive feeding for 7 days. A previous study suggested that there were individual differences in the initial locomotor response to a novel environment in rats (28). Therefore, the adaptive feeding may make rats familiar with the test environment in advance and avoid the effect of a novel environment on locomotor activity. The adaptive feeding procedure was as follows: On days 1-2, rats were housed in groups of three per cage as aforementioned; on days 3-5, the animals were acclimated to locomotor chambers (Shanghai Mobile Datum Information Technology Co., Ltd., Shanghai, China) for $1 \mathrm{~h}$; on days 6 and 7, locomotor activity was recorded for $2 \mathrm{~h}$ once a day between 8:00 and 16:00. An average baseline for locomotor activity of each rat was established and expressed as locomotor data obtained from the two tests on days 6 and 7. All experimental procedures were carried out in accordance with the 1996 National Institutes of Health Guide for the Care and Use of Laboratory Animals (29) and all experimental procedures were approved by the Institutional Animal Care and Use Committee, Capital Normal University (Beijing, China).

Apparatus. Locomotor activity was measured in a locomotor activity chamber $40 \times 40 \times 50 \mathrm{~cm}$ (length $\mathrm{x}$ width $\mathrm{x}$ height;
Shanghai Mobile Datum Information Technology Co., Ltd.). The chamber was placed in a sound attenuating, dimly illuminated container with an exhaust fan in order to avoid the interference of external unrelated conditions on rat's locomotor activity during the testing and to maintain ventilation. Locomotor activity was measured based on the horizontal distance $(\mathrm{mm})$ traveled and was recorded automatically with an infrared video-tracking system.

Drugs. The following drugs were used: sterile $0.9 \%$ saline (prepared by our laboratory) and morphine hydrochloride (10 mg/ml, Shenyang First Pharmaceutical Factory, Shenyang, China), which was diluted to $5 \mathrm{mg} / \mathrm{ml}$ in sterile saline prior to intraperitoneal injection. Huperzine A (purity $>98 \%$, Jiangxi Herbal Tiangong Technology Co., Ltd., Jiangxi, China), an acetylcholinesterase inhibitor, was dissolved in phosphate-buffered saline. The doses of huperzine A were administered at concentrations of $0.2,0.3$ and $0.4 \mathrm{mg} / \mathrm{kg}$, as described previously $(30,31)$. All drugs were injected intraperitoneally at a volume of $1 \mathrm{~m} / \mathrm{kg}$ between 8:00 and 16:00.

Procedures. Two experiments were completed to examine locomotor activity. The first was to assess the effects of huperzine A administration alone on locomotor activity. It has been demonstrated that acetylcholinesterase inhibitors decrease locomotor activity (32); therefore, a supplementary experiment was set up in the current study to examine the effects of huperzine A administration alone on locomotor activity and analyze the side effects of huperzine A on locomotor activity $(32,33)$. In the current experiment, based on the baseline data of locomotor activity obtained from the adaptive feeding phase, these baseline data were ranked from highest to lowest, and then grouped by S-type. A total of 32 rats were evenly divided into four groups ( $\mathrm{n}=8$ rats per group) and treated with: Saline (Sal), $0.2 \mathrm{mg} / \mathrm{kg}$ huperzine A (0.2 HupA), $0.3 \mathrm{mg} / \mathrm{kg}$ huperzine A (0.3 HupA) or $0.4 \mathrm{mg} / \mathrm{kg}$ huperzine A (0.4 HupA). On days $1-5$, each group was administered the corresponding injection alone (saline or huperzine A) in their cage once daily. Locomotor activity was recorded for $2 \mathrm{~h}$ starting $25 \mathrm{~min}$ (30) following each injection.

The second experiment assessed the effects of huperzine A on morphine-induced behavioral sensitization. To examine the effects of huperzine A on behavioral sensitization induced by morphine, 40 rats which were different from the rats used in the first experiment were assigned to five groups ( $n=8$ rats per group) and treated with: Saline+saline $(\mathrm{Sal}+\mathrm{Sal})$, saline $+5 \mathrm{mg} / \mathrm{kg}$ morphine (Sal+Mor), $0.2 \mathrm{mg} / \mathrm{kg}$ huperzine $\mathrm{A}+5 \mathrm{mg} / \mathrm{kg}$ morphine $(0.2$ HupA+Mor), $0.3 \mathrm{mg} / \mathrm{kg}$ huperzine $\mathrm{A}+5 \mathrm{mg} / \mathrm{kg}$ morphine $(0.3$ HupA+Mor) or $0.4 \mathrm{mg} / \mathrm{kg}$ huperzine $\mathrm{A}+5 \mathrm{mg} / \mathrm{kg}$ morphine (0.4 HupA+Mor). This experimental procedure involved three phases (Table I). The first injection was administered to all rats between 8:00 and 16:00 and the second injection was administered 25 min later (30). During the development phase (days 1-5), the rats in the Sal+Sal group received saline injections twice daily and rats in the Sal+Mor group were administered saline and morphine every day. The remaining three groups were administered different doses of huperzine $A$ and morphine every day. During the withdrawal phase (days 6-12), no treatments were administered. During the 
expression phase (day 13), all animals were administered $1 \mathrm{ml} / \mathrm{kg}$ saline to examine the effects of repeated huperzine A administration during the development phase of morphine sensitization, to determine whether relapse is induced by contextual conditioning alone. Conditioned locomotor activity induced by saline injection may be regarded as a relapse caused by contextual conditioning when this follows repeated and intermittent exposure to morphine (34). Bevins and Bardo also suggested that when a multisensory environment was reliably paired with morphine in rats, that context, in a drug-free test, could evoked a hyperactive conditioned locomotor activity (35). On day 14, all rats were challenged with $5 \mathrm{mg} / \mathrm{kg}$ morphine to determine the effects of huperzine $\mathrm{A}$ on the development of morphine-induced sensitization. On day 18, the rats in the Sal+Mor group were injected with saline and morphine $(5 \mathrm{mg} / \mathrm{kg}$ ). The other three groups received co-administration of huperzine A $(0.2,0.3$ or $0.4 \mathrm{mg} / \mathrm{kg})$ and $5 \mathrm{mg} / \mathrm{kg}$ morphine. Considering the data regarding development and morphine challenge, the current study assessed the state-dependency hypothesis using these challenges on day 18 . On day 22 , the rats in the Sal+Mor group were injected with the appropriate dose of huperzine A and $5 \mathrm{mg} / \mathrm{kg}$ morphine to examine the effect of huperzine A on the expression of morphine-induced sensitization. The preferred dose of huperzine A $(0.4 \mathrm{mg} / \mathrm{kg})$ was selected from $0.2,0.3$ and $0.4 \mathrm{mg} / \mathrm{kg}$ based on the results of preliminary experiments in the present study. On day 26, only the Sal+Mor rats were injected with saline and $5 \mathrm{mg} / \mathrm{kg}$ morphine to investigate whether sensitization was weakened or disappeared over time. Locomotor activity was recorded for $2 \mathrm{~h}$ immediately following the administration of the final injection. Particularly, in order to avoid elimination of any conditioned hyperactivity and to fully model the relapse induced by contextual conditioning, when all the groups were challenged with saline on day 13 in this experiment, their locomotor activities were recorded for $1 \mathrm{~h}$, as described previously (36-40).

Statistical analysis. Statistical analysis was performed using SPSS version 16.0 (SPSS, Inc., Chicago, IL, USA). Data are expressed as mean \pm standard error of the mean (mean \pm SEM), unless otherwise indicated. Data obtained from repeated huperzine A administration alone in experiment one and development of sensitization in experiment two were analyzed by two-way (groups $\mathrm{x}$ time) repeated measures analysis of variance (ANOVA). Data regarding the drug challenge on days 13,14 and 18 in experiment 2 were respectively analyzed by one-way ANOVA. This was followed by the least significant difference (LSD) post hoc comparison when there was significance among groups. One-way repeated measures ANOVA was used to compare the data of the Sal+Mor group on days 18,22 and 26 in experiment $2 . \mathrm{P}<0.05$ was considered to represent a statistically significant difference.

\section{Results}

Administration of huperzine A alone does not affect locomotor activity. As demonstrated by the two-way (groups $x$ time) repeated measures ANOVA, repeated huperzine A injection alone had no significant effect on locomotor activity (Fig. 1). The interaction effects of groups $x$ time 


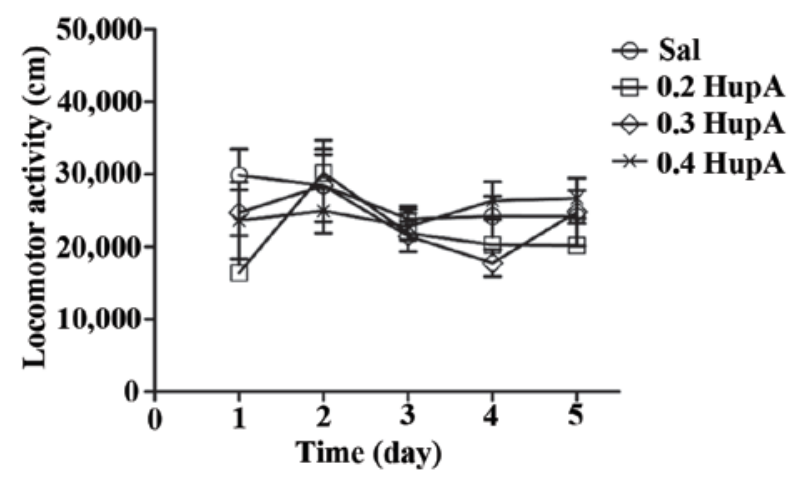

Figure 1. Effects of repeated huperzine A administration alone $(0.2,0.3$ and $0.4 \mathrm{mg} / \mathrm{kg})$ on locomotor activity. Data are expressed as mean \pm standard error of the mean. Sal, saline treated group; $0.2 \mathrm{HupA}, 0.2 \mathrm{mg} / \mathrm{kg}$ huperzine A group; $0.3 \mathrm{HupA}, 0.3 \mathrm{mg} / \mathrm{kg}$ huperzine A group; $0.4 \mathrm{HupA}, 0.4 \mathrm{mg} / \mathrm{kg}$ huperzine A group.

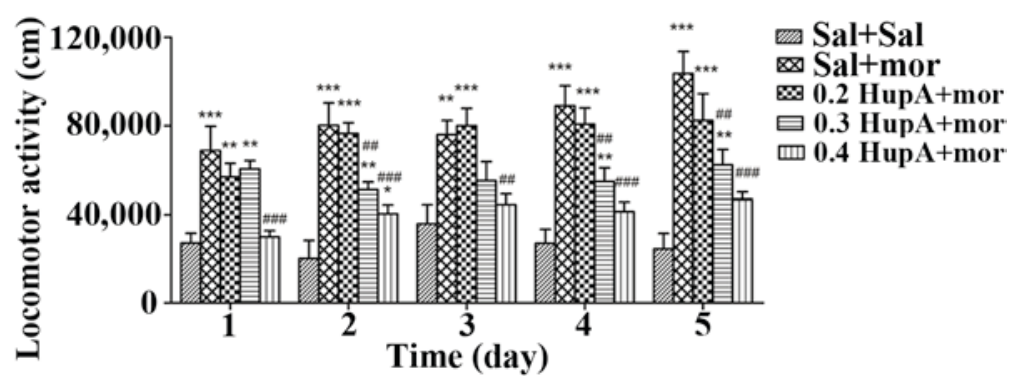

Figure 2. Effects of the co-administration of huperzine A $(0.2,0.3$ and $0.4 \mathrm{mg} / \mathrm{kg})$ and morphine on locomotor activity in the development phase of behavioral sensitization. Data are expressed as mean \pm standard error of the mean. ${ }^{*} \mathrm{P}<0.05,{ }^{* * *} \mathrm{P}<0.01$ and ${ }^{* * * *} \mathrm{P}<0.001$ vs. the Sal+Sal group; ${ }^{\# \#} \mathrm{P}<0.01$ and ${ }^{\# \# \#} \mathrm{P}<0.001$ vs. the Sal+Mor group. Sal, saline; mor, morphine; $0.2 \mathrm{HupA}, 0.2 \mathrm{mg} / \mathrm{kg}$ huperzine A group; $0.3 \mathrm{HupA}, 0.3 \mathrm{mg} / \mathrm{kg}$ huperzine A group; $0.4 \mathrm{HupA}, 0.4 \mathrm{mg} / \mathrm{kg}$ huperzine A group.

$[\mathrm{F}(12,112)=1.126, \mathrm{P}=0.346]$, the main effects of the groups $[\mathrm{F}(3,28)=0.849, \mathrm{P}=0.479]$ and time $[\mathrm{F}(4,112)=2.370$, $\mathrm{P}=0.057]$ did not have significant effects on locomotor activity $(\mathrm{P}>0.05)$. According to the average locomotor activity of days $1-5$, there was no significant difference between the Sal group and all HupA groups (0.2, 0.3 and $0.4 \mathrm{mg} / \mathrm{kg}$ ) (mean difference \pm SEM: 4,337.631 $\pm 2,873.362 ; 2,687.724 \pm 2,873.362$; $1,232.341 \pm 2,873.362 ; \mathrm{P}>0.05)$. Therefore, repeated huperzine A injection alone did not alter the motor function of the rats.

Higher doses of huperzine A immediately inhibit morphine-induced addictive behavior at the development phase. The results of two-way ANOVA indicated that the interaction effects of groups $\mathrm{x}$ time $[\mathrm{F}(16,140)=2.381$, $\mathrm{P}=0.004]$ and the main effects of the groups $[\mathrm{F}(4,35)=16.729$, $\mathrm{P}<0.001]$ and time $[\mathrm{F}(4,140)=7.131, \mathrm{P}<0.001]$ all had significant effects on locomotor activity when rats were co-administered huperzine and morphine $(\mathrm{P}<0.05)$. With respect to the daily locomotor activities of each group, the LSD post hoc comparison indicated that daily locomotor activities in the Sal+Mor group were significantly greater than those in the Sal+Sal group ( $\mathrm{P} \leq 0.001$ on days $1-5)$, which indicated that repeated morphine administration caused addictive behavior (Fig. 2). Furthermore, the daily locomotor activities in the 0.2 HupA+Mor group were significantly greater than those in the $\mathrm{Sal}+\mathrm{Sal}$ group $(\mathrm{P}=0.002$ and $\mathrm{P}<0.001$ on days 1 and $2-5$, respectively). However, compared to the Sal+Mor group, no significant difference in locomotor activity was observed in the 0.2 HupA+Mor group $(\mathrm{P}=0.194, \mathrm{P}=0.701, \mathrm{P}=0.703, \mathrm{P}=0.392$ and $\mathrm{P}=0.083$ on days $1-5$, respectively), suggesting that $0.2 \mathrm{mg} / \mathrm{kg}$ huperzine A did not prevent the locomotor behavior induced by morphine. The locomotor activities in the 0.3 HupA+Mor group were markedly increased compared to those in the Sal+Sal group $(\mathrm{P}=0.001, \mathrm{P}=0.002, \mathrm{P}=0.007$ and $\mathrm{P}=0.003$ on days 1,2, 4 and 5, respectively; except for $\mathrm{P}=0.077$ on day 3); however, they were significantly less than those in the Sal+Mor group only on days 2, 4 and $5(\mathrm{P}=0.004$, $\mathrm{P}=0.001$ and $\mathrm{P}=0.001$, respectively). These results suggested that $0.3 \mathrm{mg} / \mathrm{kg}$ huperzine A inhibited morphine-induced locomotor increases. However, the daily locomotor activities in the 0.4 HupA+Mor group were significantly lower than those in the Sal+Mor group $(\mathrm{P}<0.001, \mathrm{P}<0.001, \mathrm{P}=0.005$, $\mathrm{P}<0.001$ and $\mathrm{P}<0.001$ on days $1-5$, respectively). There were no significant differences in the locomotor activity between the 0.4 HupA+Mor group and the $\mathrm{Sal}+\mathrm{Sal}$ group $(\mathrm{P}=0.761$, $\mathrm{P}=0.417, \mathrm{P}=0.148$ and $\mathrm{P}=0.069$ on days $1,3,4$ and 5 , respectively), with the exception of day $2(\mathrm{P}=0.040)$. Therefore, $0.4 \mathrm{mg} / \mathrm{kg}$ huperzine A rapidly and effectively rescued the addictive behavior induced by morphine (Fig. 2).

Huperzine A does not inhibit the relapse induced by contextual conditioning. Saline-challenged locomotor activity was markedly different among the groups $[\mathrm{F}(4,35)=7.234$, $\mathrm{P}<0.001]$ (Fig. 3). LSD post hoc comparison analysis indicated a clear increase in locomotor activity in the Sal+Mor group compared with that in the Sal+Sal group. (mean difference \pm SEM: $25,439.104 \pm 6,318.852$, P<0.001; Fig. 3). 


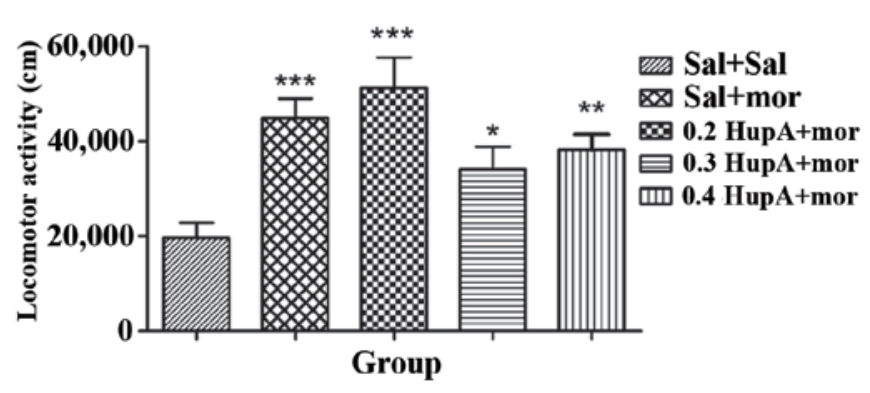

Figure 3. Effects of huperzine A on the relapse induced by contextual conditioning. Data are expressed as mean \pm standard error of the mean. ${ }^{*} \mathrm{P}<0.05$, ${ }^{* * *} \mathrm{P}<0.01$ and ${ }^{* * *} \mathrm{P}<0.001$ vs. the Sal+Sal group. Sal, saline; mor, morphine; 0.2 HupA, $0.2 \mathrm{mg} / \mathrm{kg}$ huperzine A group; $0.3 \mathrm{HupA}, 0.3 \mathrm{mg} / \mathrm{kg}$ huperzine A group; $0.4 \mathrm{HupA}, 0.4 \mathrm{mg} / \mathrm{kg}$ huperzine A group.

Similarly, the locomotor activities in the 0.2 HupA+Mor group, 0.3 HupA+Mor group and 0.4 HupA+Mor group were all significantly greater than those in the Sal+Sal group $(\mathrm{P}<0.001, \mathrm{P}=0.029$ and $\mathrm{P}=0.006$, respectively; Fig. 3); however, there were no significant differences in locomotor activity in the HupA treated groups compared with the Sal+Mor group $(\mathrm{P}=0.343, \mathrm{P}=0.088$ and $\mathrm{P}=0.280$, respectively; Fig. 3). Therefore, huperzine A did not inhibit the relapse induced by the saline challenge.

Huperzine A does not inhibit the development of morphine-induced behavioral sensitization. Considering morphine-challenged locomotor activities, a one-way ANOVA revealed a significant difference among the groups $[\mathrm{F}(4,35)=2.979, \mathrm{P}=0.032]$. The results of the LSD post hoc comparison indicated that the locomotor activity in the Sal+Mor group was significantly greater than that of the Sal+Sal group (mean difference \pm SEM: $30,567.659 \pm 12,713.000$, $\mathrm{P}=0.022$; Fig. 4), which indicated that behavioral sensitization was established. Furthermore, the locomotor activities in the 0.2 HupA+Mor group, 0.3 HupA+Mor group and $0.4 \mathrm{HupA}+\mathrm{Mor}$ group were all significantly greater than those in the Sal+Sal group $(\mathrm{P}=0.047, \mathrm{P}=0.024$ and $\mathrm{P}=0.002$, respectively; Fig. 4); however, no differences were observed when compared with the Sal+Mor group $(\mathrm{P}=0.732, \mathrm{P}=0.963$ and $\mathrm{P}=0.382$, respectively; Fig. 4). Therefore, huperzine A failed to block the development of morphine-induced behavioral sensitization.

The current study does not support the state-dependency hypothesis. When the rats in the Sal+Mor group and the three HupA+Mor groups were challenged with saline and morphine or different doses of huperzine A and morphine, the difference in locomotor activity among the groups was significant $[\mathrm{F}(3,28)=7.900, \mathrm{P}=0.001]$. LSD post hoc comparison analysis revealed that the locomotor activities in the $0.4 \mathrm{HupA}+$ Mor group were significantly lower compared with those in the Sal+Mor group (mean difference \pm SEM: 49,737.813 $\pm 10,660.000, \mathrm{P}<0.001$; Fig. 5). However, the locomotor activities in the 0.2 HupA+Mor group (mean difference \pm SEM: 13,219.521 $\pm 10,660.000$, $\mathrm{P}=0.225$ ) and 0.3 HupA+Mor group (mean difference $\pm \mathrm{SEM}$ : $15,830.700 \pm 10,660.000, \mathrm{P}=0.149$ ) did not differ significantly to those in the Sal+Mor group (P>0.05; Fig. 5). Based on the

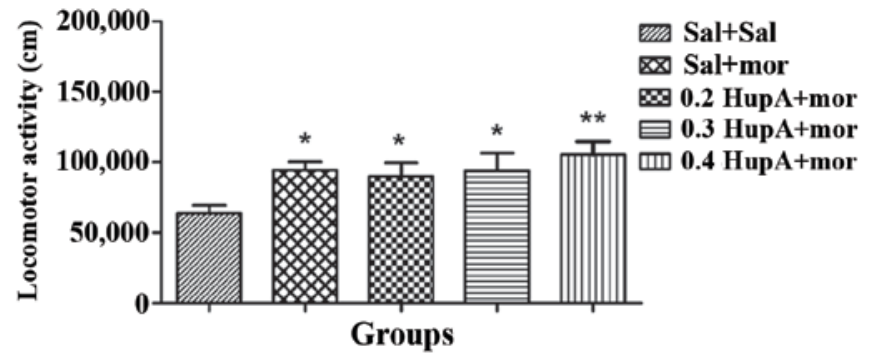

Figure 4. Effects of huperzine A on the development of morphine-induced behavioral sensitization. Data are expressed as mean \pm standard error of the mean. ${ }^{*} \mathrm{P}<0.05$ and $^{* *} \mathrm{P}<0.01$ vs. the Sal+Sal group. Sal, saline; mor, morphine; 0.2 HupA, $0.2 \mathrm{mg} / \mathrm{kg}$ huperzine A group; $0.3 \mathrm{HupA}, 0.3 \mathrm{mg} / \mathrm{kg}$ huperzine A group; 0.4 HupA, $0.4 \mathrm{mg} / \mathrm{kg}$ huperzine A group.

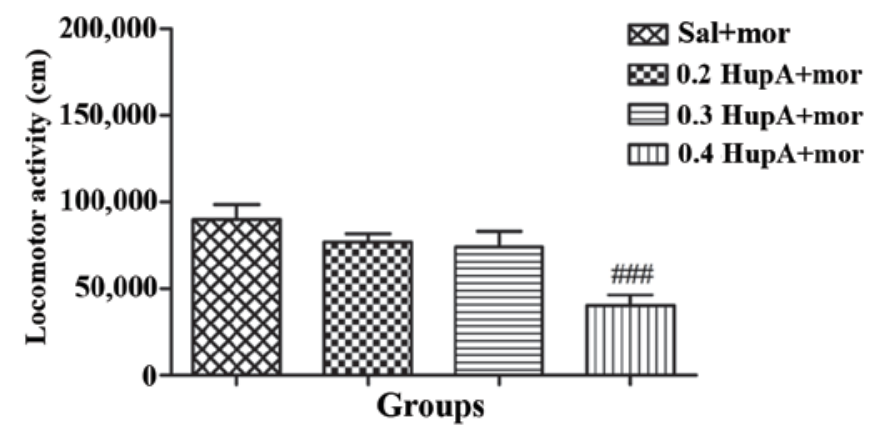

Figure 5. Examination of the state-dependency hypothesis. The rats in the Sal+Mor group and the three HupA+Mor groups were challenged with saline and morphine and the corresponding dose of huperzine A $(0.2$, 0.3 and $0.4 \mathrm{mg} / \mathrm{kg}$ ) and morphine, respectively. Data are expressed as mean \pm standard error of the mean. ${ }^{\# \# \#} \mathrm{P}<0.001$ vs. the Sal+Mor group. Sal, saline; mor, morphine; 0.2 HupA, $0.2 \mathrm{mg} / \mathrm{kg}$ huperzine A group; $0.3 \mathrm{HupA}$, $0.3 \mathrm{mg} / \mathrm{kg}$ huperzine A group; $0.4 \mathrm{HupA}, 0.4 \mathrm{mg} / \mathrm{kg}$ huperzine A group.

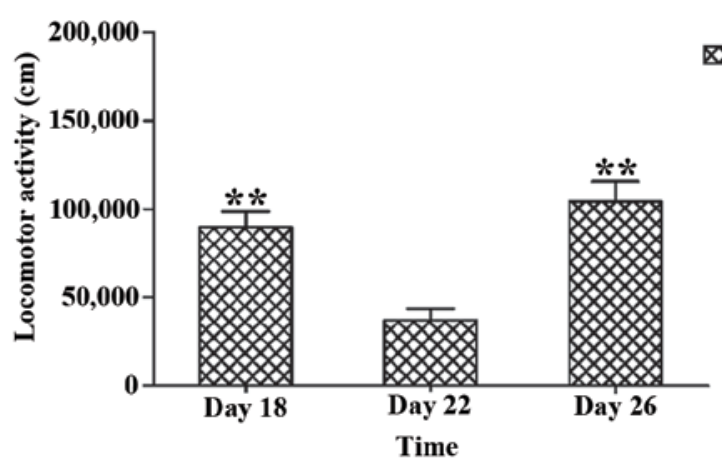

Figure 6. Effects of huperzine A on the expression of morphine sensitization in the Sal+Mor group. On day 18, the rats in the Sal+Mor group were injected with saline and $5 \mathrm{mg} / \mathrm{kg}$ morphine. On day 22 , rats were injected with $0.4 \mathrm{mg} / \mathrm{kg}$ huperzine A and $5 \mathrm{mg} / \mathrm{kg}$ morphine to examine the effect of huperzine A on the expression of morphine-induced sensitization. On day 26, rats were injected with saline and $5 \mathrm{mg} / \mathrm{kg}$ morphine again to investigate whether sensitization weakened or disappeared with time. Data are expressed as mean \pm standard error of the mean. ${ }^{* *} \mathrm{P}<0.01$ vs. locomotor activity challenged with $0.4 \mathrm{mg} / \mathrm{kg}$ huperzine A and morphine on day 22. Sal, saline; mor, morphine.

5-day locomotor activity data obtained from the development phase and the morphine-challenged locomotor activity data from the expression phase, state-dependency was not supported by these results. 
A higher dose of huperzine A inhibits the expression of morphine-induced behavioral sensitization. Based on the aforementioned findings, $0.4 \mathrm{mg} / \mathrm{kg}$ huperzine $\mathrm{A}$, as the preferred dose, was used in the following experiment. A one-way repeated measures ANOVA demonstrated that time had a significant influence on locomotor activity $[\mathrm{F}(2,14)=13.367, \mathrm{P}=0.001]$. With regard to the Sal+Mor group, the results of LSD post hoc comparison analysis indicated that the locomotor activity measured following co-administration of $0.4 \mathrm{mg} / \mathrm{kg}$ huperzine A and morphine on day 22 was significantly lower than the group challenged with saline and morphine on day 18 (mean difference \pm SEM: $-52,622.189 \pm 14,140.000, P=0.007$; Fig. 6 ) and the group challenged with saline and morphine on day 26 (mean difference \pm SEM: $-67,220.744 \pm 12,160.000, P=0.001$; Fig. 6) However, no significant difference was observed between the locomotor activities on days 18 and 26 (mean difference \pm SEM: $-14,598.555 \pm 14,610.000, \mathrm{P}=0.351$; Fig. 6). Consequently, it was determined that $0.4 \mathrm{mg} / \mathrm{kg}$ huperzine A inhibited the expression of morphine-induced behavioral sensitization.

\section{Discussion}

In the present study, three different doses of huperzine A, which were co-administered with morphine during the development of the sensitization phase (days 1-5), failed to inhibit locomotor activity when morphine challenge was instigated on day 14 This indicates that huperzine A did not stop the development of morphine-induced behavioral sensitization. Notably, during the 5-day development of sensitization, $0.4 \mathrm{mg} / \mathrm{kg}$ huperzine A blocked the increase in locomotor activities caused by morphine. Additionally, considering the evidence indicating that the three different doses of huperzine A did not affect the motor function of the animals, it is likely that the inhibition of $0.4 \mathrm{mg} / \mathrm{kg}$ huperzine A on morphine-induced hyperactivity during the 5-day developmental phase was immediate and temporary. Locomotor activity in the 0.4 HupA+Mor group was significantly higher when challenged with morphine compared with the Sal+Sal group. It was demonstrated that sensitization developed normally.

Previous studies have demonstrated that acetylcholinesterase inhibitors may markedly affect cholinergic interneurons in the striatum $(41,42)$. Furthermore, the balance between dopamine and acetylcholine in the striatum may modulate motor function (43). Therefore, the immediate suppression of locomotor activities was potentially induced by simultaneous inhibition of dopamine release caused by morphine and acetylcholine release following huperzine A administration in the striatum. However, this alternative hypothesis and mechanism of the immediate inhibition of huperzine A requires additional investigation.

The appearance of addictive behavior during the development of sensitization was prevented by $0.4 \mathrm{mg} / \mathrm{kg}$ huperzine; however, it remains unknown why the initial inhibition by huperzine A did not last longer. By contrast, the development of behavioral sensitization was associated with external factors, including the frequency, dose, interval and contextual conditioning of injections (44) in addition to the insufficient frequency of administration and the short development period in the present study. This may have resulted in a temporary inhibitory effect. With regard to the Sal+Mor group, the locomotor activity induced by co-administration of
$0.4 \mathrm{mg} / \mathrm{kg}$ huperzine A and morphine on day 22 was not as marked compared with the group challenged with saline and morphine on day 18 . This indicates that $0.4 \mathrm{mg} / \mathrm{kg}$ huperzine A may suppress the expression of behavioral sensitization caused by morphine, which was in agreement with the results obtained from previous studies investigating other acetylcholinesterase inhibitors, such as physostigmine (17).

The locomotor activity in the Sal+Mor group challenged with saline and morphine on day 26 increased significantly again, indicating that behavioral sensitization was not weakened or eliminated with time and confirming the inhibitory effect of $0.4 \mathrm{mg} / \mathrm{kg}$ huperzine $\mathrm{A}$ on the expression of morphine-induced behavioral sensitization. However, huperzine A failed to inhibit the development of morphine-induced behavioral sensitization. This phenomenon may be explained by the different mechanisms of development and expression of morphine-induced behavioral sensitization (45). The development of morphine sensitization primarily requires stimulation of $\mu$-opioid receptors within the ventral tegmental area but not the dopamine receptor $(46,47)$. However, its expression requires stimulation of the dopamine receptor, specifically the dopamine $\mathrm{D}_{2}$ receptor (47). Furthermore, the nucleus accumbens has been recognized as the brain region that is most closely associated with the expression of behavioral sensitization (48). Repeated morphine administration may enhance the release of dopamine, which may stimulate the dopamine $\mathrm{D}_{2}$ receptor $(45,47)$, leading to an increase in locomotor activities. The increasing concentration of acetylcholine in the nucleus accumbens may suppress the addictive behavior caused by morphine (10). It has been demonstrated that acetylcholinesterase inhibitors administered to the nucleus accumbens, but not to the ventral tegmental area, suppress the rewarding response to opioids $(10,49)$. Thus, huperzine A potentially increased the release of acetylcholine, which may inhibit the release of dopamine in the nucleus accumbens, resulting in a blockade of expression for behavioral sensitization induced by morphine.

The present study demonstrated that three different doses of huperzine A $(0.2,0.3$ and $0.4 \mathrm{mg} / \mathrm{kg})$, which were injected with morphine during development of the sensitization phase (days 1-5), failed to suppress relapse when challenged with saline alone on day 13. As huperzine A did not stop the development of morphine sensitization, the contextual conditioning that is associated with the drug rewarding may have potentially possessed 'incentive salience' $(12,50)$ and the reward-associated contextual conditioning may induce relapse (23). Incentive salience, just as a psychological process, transforms the perception of stimuli, imbuing them with salience, making them attractive, 'wanted', incentive stimuli (12). By contrast, huperzine A may be selectively distributed in the cerebral cortex, hippocampus and other brain regions associated with learning and memory $(2,51)$. In particular, the hippocampus is involved in the conditioning of contextual stimuli, contextual learning and memory consolidation $(22,23)$. Therefore, huperzine A may enhance the release of acetylcholine in the central nervous system and improve the normal or impaired learning and memory functions of animals (31,52-54). Consequently, contextual conditioning was more closely associated with relapse.

The state-dependency hypothesis was previously used to interpret the following phenomenon: Rats repeatedly injected 
with MK-801 and bromocriptine exhibited progressive augmentation of locomotor activities during the development phase $(24,27)$. However, the rats did not exhibit sensitized behavior when they were challenged with bromocriptine alone, until they were challenged with MK-801+bromocriptine (25). Carlezon et al (25) and Wise et al (26) suggested that MK-801 became a conditioned stimulus to recall the sensitized response only when co-administered with bromocriptine during a challenge period. The contextual dependency of sensitization was extended to the drug state when sensitization was induced (27).

In contrast to the results obtained from the aforementioned previous studies (25), the present study demonstrated that locomotor activity in the 0.4 HupA+Mor group was prevented when $0.4 \mathrm{mg} / \mathrm{kg}$ huperzine $\mathrm{A}$ and morphine were injected in the development and expression phases, but did not experience behavioral sensitization. Following withdrawal, 0.4 HupA+Mor rats expressed sensitized behavior when challenged with morphine alone, but did not exhibit inhibition of behavior. Therefore, the results of the present study do not support the state-dependency hypothesis. As discussed, the inhibition of huperzine A on behavioral sensitization in the present study was potentially due to the unique pharmacological effects of huperzine $\mathrm{A}$ on the central nervous system or different mechanisms between the development and expression of morphine-induced behavioral sensitization.

In conclusion, the present study examined the effects of huperzine A on behavioral sensitization induced by morphine and relapse induced by contextual conditioning. The current study demonstrated that $0.4 \mathrm{mg} / \mathrm{kg}$ huperzine A may inhibit the expression of behavioral sensitization induced by morphine but not the development of sensitization. Additionally, co-administration of huperzine A with morphine during the development period did not inhibit the relapse induced by contextual conditioning. Therefore, the results of the current study did not support the state-dependency hypothesis. The inhibition mechanisms of huperzine A on morphine-induced behavioral sensitization require further investigation.

\section{Acknowledgements}

The present study was supported by the National Natural Science Foundation of China (grant no. 31470989).

\section{References}

1. Wang R, Yan H and Tang XC: Progress in studies of huperzine A, a natural cholinesterase inhibitor from Chinese herbal medicine. Acta Pharmacol Sin 27: 1-26, 2006.

2. Ma T, Gong K, Yan Y, Zhang L, Tang P, Zhang X and Gong Y: Huperzine A promotes hippocampal neurogenesis in vitro and in vivo. Brain Res 1506: 35-43, 2013.

3. Yang Y, Yang J and Jiang Q: The protective effect of huperzine A against hepatic ischemia reperfusion injury in mice. Transplant Proc 46: 1573-1577, 2014

4. Ou LY, Tang XC and Cai JX: Effect of huperzine A on working memory in reserpine- or yohimbine-treated monkeys. Eur J Pharmacol 433: 151-156, 2001.

5. Zhang HY, Yan $\mathrm{H}$ and Tang XC: Non-cholinergic effects of huperzine A: Beyond inhibition of acetylcholinesterase. Cell Mol Neurobiol 28: 173-183, 2008.

6. Tang XC: Huperzine A (shuangyiping): A promising drug for Alzheimer's disease. Zhongguo Yao Li Xue Bao 17: 481-484, 1996.
7. Liang YQ and Tang XC: Comparative effects of huperzine A, donepezil and rivastigmine on cortical acetylcholine level and acetylcholinesterase activity in rats. Neurosci Lett 361: 56-59, 2004.

8. Zhang HY and Tang XC: Neuroprotective effects of huperzine A: New therapeutic targets for neurodegenerative disease. Trends Pharmacol Sci 27: 619-625, 2006.

9. Ma X and Gang DR: In vitro production of huperzine A, a promising drug candidate for Alzheimer's disease. Phytochemistry 69: 2022-2028, 2008.

10. Hikida T, Kitabatake Y, Pastan I and Nakanishi S: Acetylcholine enhancement in the nucleus accumbens prevents addictive behaviors of cocaine and morphine. Proc Natl Acad Sci USA 100: 6169-6173, 2003

11. Handal M, Ripel A, Skurtveit S and Mørland J: Behavioural sensitization in mice induced by morphine-glucuronide metabolites. Pharmacol Biochem Behav 90: 578-585, 2008.

12. Robinson TE and Berridge $\mathrm{KC}$ : The neural basis of drug craving: An incentive-sensitization theory of addiction. Brain Res Brain Res Rev 18: 247-291, 1993.

13. Pierce RC and Kalivas PW: Repeated cocaine modifies the mechanism by which amphetamine releases dopamine. J Neurosci 17: 3254-3261, 1997.

14. Sanchis-Segura $C$ and Spanagel R: Behavioural assessment of drug reinforcement and addictive features in rodents: An overview. Addict Biol 11: 2-38, 2006.

15. Tortorelli LS, Engelke DS, Lunardi P, Mello E Souza T, Santos-Junior JG and Gonçalves CA: Cocaine counteracts LPS-induced hypolocomotion and triggers locomotor sensitization expression. Behav Brain Res 287: 226-229, 2015.

16. Didone V, Quoilin C, Tirelli E and Quertemont E: Parametric analysis of the development and expression of ethanol-induced behavioral sensitization in female Swiss mice: Effects of dose, injection schedule and test context. Psychopharmacology (Berl) 201: 249-260, 2008.

17. Li X, Li JX, Zhu X, Cui R and Jiao J: Effects of physostigmine on the conditioned hyperactivity and locomotor sensitization to morphine in rats. Behav Brain Res 206: 223-228, 2010.

18. Ball KT, Klein JE, Plocinski JA and Slack R: Behavioral sensitization to 3,4-methylenedioxymethamphetamine is long-lasting and modulated by the context of drug administration. Behav Pharmacol 22: 847-850, 2011.

19. Collins GT, Truong YN, Levant B, Chen J, Wang S and Woods JH: Behavioral sensitization to cocaine in rats: Evidence for temporal differences in dopamine D3 and D2 receptor sensitivity. Psychopharmacology (Berl) 215: 609-620, 2011.

20. Zhang Q, Li JX, Zheng JW, Liu RK and Liang JH: L-type Ca(2+) channel blockers inhibit the development but not the expression of sensitization to morphine in mice. Eur J Pharmacol 467: 145-150, 2003.

21. Brody AL, Mandelkern MA, London ED, Childress AR, Lee GS, Bota RG, Ho ML, Saxena S, Baxter LR Jr, Madsen D and Jarvik ME: Brain metabolic changes during cigarette craving. Arch Gen Psychiatry 59: 1162-1172, 2002.

22. Weiss F: Neurobiology of craving, conditioned reward and relapse. Curr Opin Pharmacol 5: 9-19, 2005.

23. Zironi I, Burattini C, Aicardi G and Janak PH: Context is a trigger for relapse to alcohol. Behav Brain Res 167: 150-155, 2006.

24. Schulteis G, Liu J, Amitai N and Tzeng S: Context- and cue-conditioned potentiation of acute morphine dependence and withdrawal. Pharmacol Biochem Behav 82: 82-89, 2005.

25. Carlezon WA Jr, Mendrek A and Wise RA: MK-801 disrupts the expression but not the development of bromocriptine sensitization: A state-dependency interpretation. Synapse 20: 1-9, 1995.

26. Wise RA, Mendrek A and Carlezon WA Jr: MK-801 (dizocilpine): Synergist and conditioned stimulus in bromocriptine-induced psychomotor sensitization. Synapse 22: 362-368, 1996.

27. Stephens DN, Elliman TD and Dunworth SJ: State-dependent behavioural sensitization: Evidence from a chlordiazepoxide state. Behav Pharmacol 11: 161-167, 2000.

28. Gancarz AM, San George MA, Ashrafioun L and Richards JB: Locomotor activity in a novel environment predicts both responding for a visual stimulus and self-administration of a low dose of methamphetamine in rats. Behav Processes 86: 295-304, 2011.

29. Institute of Laboratory Animal Resources; Commission on Life Sciences; National Research Council: Guide for the Care and Use of Laboratory Animals. National Academy Press, Washington, D.C, 1996. 
30. Ye JW, Shang YZ, Wang ZM and Tang XC: Huperzine A ameliorates the impaired memory of aged rat in the Morris water maze performance. Acta Pharmacol Sin 21: 65-69, 2000.

31. Wang ZF, Tang LL, Yan H, Wang YJ and Tang XC: Effects of huperzine A on memory deficits and neurotrophic factors production after transient cerebral ischemia and reperfusion in mice. Pharmacol Biochem Behav 83: 603-611, 2006.

32. Myhrer T, Enger S and Aas P: Behavioral side effects in rats treated with acetylcholinesterase inhibitors suggested used as prophylactics against nerve agents. Pharmacol Biochem Behav 95: 338-343, 2010.

33. Gawel K, Labuz K, Jenda M, Silberring J and Kotlinska JH: Influence of cholinesterase inhibitors, donepezil and rivastigmine on the acquisition, expression and reinstatement of morphine-induced conditioned place preference in rats. Behav Brain Res 268: 169-176, 2014.

34. Lee JL, Milton AL and Everitt BJ: Cue-induced cocaine seeking and relapse are reduced by disruption of drug memory reconsolidation. J Neurosci 26: 5881-5887, 2006.

35. Bevins RA and Bardo MT: Morphine-conditioned changes in locomotor activity: Role of the conditioned stimulus. Exp Clin Psychopharm 6: 131-138, 1998.

36. Xinwang L, Aihong X, Bin Z, Ping Y and Chunyan G: Physostigmine blocks behavioral locomotor sensitization induced by morphine in rats. Acta Psychologica Sinica 37: 362-365, 2005.

37. Xinwang L, Aihong X, Bin Y, Jia W, and Chunyan G: Effects of scopolamine on behavioral sensitization induced by morphine in rats. Acta Psychologica Sinica 39: 299-305, 2007.

38. Bevins RA, Besheer J and Pickett KS: Nicotine-conditioned locomotor activity in rats: Dopaminergic and GABAergic influences on conditioned expression. Pharmacol Biochem Behav 68: $135-145,2001$

39. Reid MS, Ho LB and Berger SP: Behavioral and neurochemical components of nicotine sensitization following 15-day pretreatment: Studies on contextual conditioning. Behav Pharmacol 9: 137-148, 1998

40. Wei S and Li X: Differential effects of propranolol on conditioned hyperactivity and locomotor sensitization induced by morphine in rats. Sci Rep 4: 3786, 2014.

41. Kawaguchi Y, Wilson CJ, Augood SJ and Emson PC: Striatal interneurones: Chemical, physiological and morphological characterization. Trends Neurosci 18: 527-535, 1995.

42. Zhao Q and Tang XC: Effects of huperzine A on acetylcholinesterase isoforms in vitro: Comparison with tacrine, donepezil, rivastigmine and physostigmine. Eur J Pharmacol 455: 101-107, 2002.
43. Nakanishi S, Kaneko S, Hikida T, Watanabe D and Pastan I: Role of synaptic integration of dopaminergic and cholinergic transmission in basal ganglia function. International Congress Series 1250: 487-492, 2003.

44. Powell KR and Holtzman SG: Parametric evaluation of the development of sensitization to the effects of morphine on locomotor activity. Drug Alcohol Depend 62: 83-90, 2001.

45. Kalivas PW and Stewart J: Dopamine transmission in the initiation and expression of drug- and stress-induced sensitization of motor activity. Brain Res Brain Res Rev 16: 223-244, 1991.

46. Vezina P and Stewart J: The effect of dopamine receptor blockade on the development of sensitization to the locomotor activating effects of amphetamine and morphine. Brain Res 499: 108-120, 1989.

47. Jeziorski M and White FJ: Dopamine receptor antagonists prevent expression, but not development, of morphine sensitization. Eur J Pharmacol 275: 235-244, 1995.

48. Brady AM, Glick SD and O'Donnell P: Changes in electrophysiological properties of nucleus accumbens neurons depend on the extent of behavioral sensitization to chronic methamphetamine. Ann N Y Acad Sci 1003: 358-363, 2003.

49. Rezayof A, Nazari-Serenjeh F, Zarrindast MR, Sepehri H and Delphi L: Morphine-induced place preference: Involvement of cholinergic receptors of the ventral tegmental area. Eur J Pharmacol 562: 92-102, 2007.

50. Robinson TE and Berridge KC: Addiction. Annu Rev Psychol 54: 25-53, 2003.

51. Tang XC and Han YF: Pharmacological profile of uperzine A, a novel acetylcholinesterase inhibitor from Chinese herb. CNS Drug Reviews 5: 281- 300, 1999.

52. Tang XC, Han YF, Chen XP and Zhu XD: Effects of huperzine $\mathrm{A}$ on learning and the retrieval process of discrimination performance in rats. Zhongguo Yao Li Xue Bao 7: 507-511, 1986 (In Chinese).

53. Xiong ZQ and Tang XC: Effect of huperzine A, a novel acetylcholinesterase inhibitor, on radial maze performance in rats. Pharmacol Biochem Behav 51: 415-419, 1995.

54. Blake MG, Krawczyk MC, Baratti CM and Boccia MM: Neuropharmacology of memory consolidation and reconsolidation: Insights on central cholinergic mechanisms. J Physiol Paris 108: 286-291, 2014 